\title{
New Parameter-Uniform Discretisations of Singularly Perturbed Volterra Integro-Differential Equations
}

\author{
Bakulikira C. Iragi and Justin B. Munyakazi* \\ Department of Mathematics and Applied Mathematics, University of the Western Cape, Private Bag X17, Bellville 7535, South Africa
}

Received: 7 Jun. 2017, Revised: 20 Mar. 2018, Accepted: 23 Mar. 2018

Published online: 1 May 2018

\begin{abstract}
We design and analyse two numerical methods namely a fitted mesh and a fitted operator finite difference methods for solving singularly perturbed Volterra integro-differential equations. The fitted mesh method we propose is constructed using a finite difference operator to approximate the derivative part and some suitably chosen quadrature rules for the integral part. To obtain a parameter-uniform convergence, we use a piecewise-uniform mesh of Shishkin type. On the other hand, to construct the fitted operator method, the Volterra integro-differential equation is discretised by introducing a fitting factor via the method of integral identity with the use of exponential basis function along with interpolating quadrature rules [2]. The two methods are analysed for convergence and stability. We show that the two methods are robust with respect to the perturbation parameter. Two numerical examples are solved to show the applicability of the proposed schemes.
\end{abstract}

Keywords: Singularly perturbed problems, Volterra integro-differential equations, boundary layer, finite difference schemes, uniform convergence, error bound

\section{Introduction}

In this paper, we study the singularly perturbed Volterra integro-differential problem (SPVIDE)

$$
\begin{aligned}
L u: & =\varepsilon u^{\prime}(t)+a(t) u(t)+\int_{0}^{t} K(t, s) u(s) d s=f(t), \\
t \in I: & =[0,1] \\
u(0) & =\gamma_{0},
\end{aligned}
$$

where $\gamma_{0}$ is a given constant and the singular perturbation parameter $\varepsilon$ is assumed to take arbitrary small values $0<$ $\varepsilon \leq 1$. The coefficient $a(t)$ is a sufficiently smooth function on $I$, such that $a(t) \geq \alpha>0$. The functions $f(t)$ and $K(t, s)$ are sufficiently smooth on $I$ and $I \times I$ respectively.

Putting $\varepsilon=0$ in equation (1.1) we obtain the reduced equation

$$
a(t) u_{0}(t)+\int_{0}^{t} K(t, s) u_{0}(s) d s=f(t)
$$

which is a Volterra integral equation of the second kind. The singularly perturbed character of (1.1) occurs when the properties of the solution with $\varepsilon \neq 0$ are not in accordance with those when $\varepsilon=0$. This incompatibility gives rise to an initial layer.

These problems often arise in various areas, for instance, in models of population dynamics, epidemics, diffusion with nonlinear surface dissipation, synchronous control systems and nonlinear renewal processes, filament stretching, polymer rheology, nonlinear radiation heat transfer (see, e.g., $[2,13]$ and references quoted).

It is known that, unless severe restrictions are made on the step size of a discretisation, most of the classical numerical methods are not fit to handle problems with a small parameter multiplying the derivative. The truncation error becomes unbounded as the perturbation parameter gets small. To resolve this issue, two approaches are often used in the framework of finite difference methods. The first approach, usually named fitted mesh finite difference methods, consists of an upwinding scheme as a discretisation on a nonuniform mesh. The second approach which forms the class of fitted operator finite difference methods recourses to a discrete operator involving either a fitting factor (of exponential type for example) or a denominator function. The above approaches have been used extensively to solve singularly perturbed differential equations.

* Corresponding author e-mail: jmunyakazi@uwc.ac.za 
However, very little effort in their use is observed for singularly perturbed integro-differential equations.

Numerous works on numerical treatment of Volterra/Fredholm integral equations have been recorded in the literature over the past half century.

Kauthen [9] surveyed the existing litterature on singularly perturbed Volterra integral and integro-differential equations. He also analysed an implicit Runge-Kutta method for singularly perturbed Volterra integro-differential equation [7]. whilst in [8] the same author studied the convergence of the extended implicit Pouzet-Volterra-Runge-Kutta methods applied to singularly perturbed systems of Volterra integro-differential equations. An exponential fitted scheme for a fixed perturbation parameter $\varepsilon$ is derived and stability analyis of the scheme is discussed in [15]. The discretization of singularly perturbed Volterra integro-differential equation and Volterra integral equations by tension spline collocation methods in tension spline spaces can be found in [6].

A general overview of several techniques to integrate Volterra/Fredholm integral or integro-differential equations can be found in $[1,11,12,14,17]$. In 2006 Bijura[5] demonstrated the existence of the initial layers whose thickness is not of order of magnitude $O(\varepsilon), \varepsilon \longmapsto$ 0 , and developed approximate solutions using the initial layer theory In [16], Şevgin studied the convergence properties of a difference scheme for singularly perturbed Volterra integro-differential equations on a graded mesh. Zhongdi and Lifeng [18] used the midpoint difference operator along with trapezoidal integration on a piecewise uniform Shishkin mesh to develop the numerical method for (1.1)-(1.2). They discussed the convergence of the method and showed that the proposed method is almost second convergence. On the other hand, Amiraliyev and Şevgin [2] presented an exponentially fitted finite difference method to solve the same problem. The fitting factor was intoduced via the method of integral identities with the use of exponential basis functions and interpolating quadrature rules with weight and remainder terms in integral form. Their method was first order accurate.

In this paper, we introduce two discretisations of (1.1)-(1.2). Firstly, we use the upwinding scheme and a combination of the right side rectangle and trapezoidal rules on a piecewise uniform mesh of Shishkin type. We refer to this method as the fitted mesh finite difference method (FMFDM) for (1.1)-(1.2). Kudu et al. [10] designed an implicit finite difference scheme on a piecewise uniform mesh of Shishkin-type for solving a singularly perturbed delay integro-differential equation. However, he did not use the trapezoidal rule.

Secondly, based on the method of integral identities and the use of exponential basis functions we compute a fitting factor which is used to discretise the differential part of (1.1)-(1.2). Then, a blend of some suitable interpolating quadrature rules with weight and remainder terms in the integral form are used for the integral part.
This approach is termed exponentially fitted operator finite difference method (EFOFDM). A similar numerical approach has been proposed by Amiralivey and Şevgin [2].

Thus, the approach to construct difference problems and analyze the error for approximate the solutions is analogous to the ones from [2], [10] and [16] and based upon some quadrature rules introduced by Amiraliyev [3]. An extension and summary of these rules are given in Amiraliyev and Mamedou [4].

The proposed methods are analysed for convergence and stability and are shown to be first order accurate.

Before we proceed further, we present a lemma which will be useful in the analysis of the methods introduced in subsequent sections.

Lemma 11The solution $u(t)$ of problem (1.1)-(1.2) satisfies the estimate

$$
\left|u^{(k)}\right| \leq C\left(1+\varepsilon^{-k} \exp (-\alpha t / \varepsilon)\right) \quad t \in I, \quad 0 \leq k \leq 3 .
$$

Prof. See [2]

The rest of the paper is structured as follows: The fitted mesh method is given in Section 2. In 2.1, we introduce the Shishkin mesh and describe the finite difference scheme. The convergence properties of the fitted mesh method is analysed in 2.2. Section 3, deals with the exponential fitted operator method. In 3.1, the difference scheme is developed on a uniform mesh. The stability and convergence of the exponential fitted operator is provided in 3.2. In 3.3, we carry out the error analyis of the exponential scheme. Two test examples are presented in Section 4. Some concluding remarks and discussion are given in Section 5.

\section{Notation}

For a positive $N$, we adopt the following notations. Let $\psi_{N}=\left\{t_{0}=0<t_{1}<t_{2}<t_{3}<\ldots<t_{N-1}<t_{N}=1\right\}, \bar{\psi}_{N}=$ $\psi_{N} \cup\{t=0\}$, be a partition of $[0,1]$ and for each $i \geq 1$, we set the mesh widths $h_{i}=t_{i}-t_{i-1}$. Throughout the paper, the notation $g_{\widetilde{t}, i}=\left(g_{i}-g_{i-1}\right) / h_{i}$ is used for any mesh function $g_{i}$ defined on $\psi_{N}$ and $C$ denotes a generic constant that is independent of the perturbation parameter $\varepsilon$ and of the mesh step-size $h_{i}$. To simplify the notation we set $g_{i}=g\left(t_{i}\right)$ for any function $g(t)$ and utilize the maximum norm defined by $\|g\|_{\infty}=\max _{[0,1]}|g(t)|$. Furthermore, for any discrete function $g_{i}$, we denote the corresponding discrete norm by $\|g\|_{\infty, \psi_{N}} \equiv\|g\|_{\infty}=\max _{[0,1]}\left|g_{i}\right|$.

\section{Method I: FMFDM}

In this section we decribe the finite difference scheme and introduce the piecewise uniform mesh. Next we present some features of the scheme and lastly we present the error analysis of the scheme. The approach we present here was derived using a method based upon the finite 
difference operator for the first derivative on Shishkin meshes along with the right side rectangle and repeated trapezoidal quadrature rules.

\subsection{The discretisation}

A fitted mesh method for solving the SPVIDE (1.1)-(1.2) is now outlined. On $\psi_{N}$ a piecewise uniform mesh of Shishkin type is constructed as follows: the domain $I=[0,1]$ is partitioned into two subdomains $[0, \lambda] \cup[\lambda, 1]$. On each of the subdomains a uniform mesh with $N / 2$ mesh intervals is established. The mesh transition point satisfies

$\lambda=\min \left\{1 / 2, \alpha^{-1} \varepsilon|\ln \varepsilon|\right\}$.

In the rest of the paper, we assume that $\lambda=\alpha^{-1} \varepsilon|\ln \varepsilon|$ so that the mesh is fine on $[0, \lambda]$ and coarse in $[\lambda, 1]$. Then our mesh points are

$t_{i}=\left\{\begin{array}{l}-\alpha^{-1} \varepsilon \ln \left[1-(1-\varepsilon) \frac{2 i}{N}\right], \quad i=0(1) N / 2, \\ \lambda+\frac{2(1-\lambda)}{N}\left(i-\frac{N}{2}\right), \quad i=N / 2+1(1) N .\end{array}\right.$

To construct the fitted mesh scheme for solving (1.1)(1.2), we integrate (1.2) over the open interval $\left(t_{i-1}, t_{i}\right)$

$$
\begin{array}{r}
\varepsilon h_{i}^{-1} \int_{t_{i}-1}^{t_{i}} u^{\prime}(t) d t+h_{i}^{-1} \int_{t_{i}-1}^{t_{i}} a(t) u(t) d t+ \\
h_{i}^{-1} \int_{t_{i}-1}^{t_{i}}\left\{\int_{0}^{t} K(t, s) u(s) d s\right\} d t=h_{i}^{-1} \int_{t_{i}-1}^{t_{i}} f(t) d t .
\end{array}
$$

Using the right side rectangle rule, we have

$\varepsilon u_{\tilde{t}, i}+a_{i} u_{i}+h_{i}^{-1}\left(t_{i}-t_{i-1}\right) \int_{0}^{t_{i}} K\left(t_{i}, s\right) u(s) d s+R_{i}^{(1)}+R_{i}^{(2)}=f_{i}$,

where

$R_{i}^{(1)}=-h_{i}^{-1} \int_{t_{i-1}}^{t_{i}}\left(t-t_{i-1}\right) \frac{d}{d t}[a(t) u(t)-f(t)] d t$,

and

$$
R_{i}^{(2)}=-h_{i}^{-1} \int_{t_{i-1}}^{t_{i}}\left(t-t_{i-1}\right) \frac{d}{d t}\left[\int_{0}^{t} K(t, s) u(s) d s\right] d t .
$$

Moreover, applying the repeated trapezoidal integration to the right-hand-side integral term in (2.6) we get

$$
\begin{aligned}
& \int_{0}^{t_{i}} K\left(t_{i}, s\right) u(s) d t=\frac{h_{i}}{4} K\left(t_{i}, t_{i}\right) u_{i}+\frac{h_{i}}{4} K\left(t_{i}, t_{i-1}\right) u_{i-1} \\
& +\sum_{j=1}^{i-1} \frac{h_{j}}{2}\left[K\left(t_{i}, t_{j}\right) u_{j}+K\left(t_{i}, t_{j-1}\right) u_{j-1}\right],
\end{aligned}
$$

where

$R_{i}^{(3)}=\sum_{j=1}^{i} \int_{t_{j-1}}^{t_{j}}\left(t_{j}-s\right) \frac{d}{d s}\left[K\left(t_{i}, s\right) u(s)\right] d s$.
Clearly from (2.6) and (2.9) we have the following expression for $u\left(t_{i}\right)$

$$
\begin{aligned}
& \varepsilon u_{\widetilde{t}, i}+a_{i} u_{i}+\frac{h_{i}}{4} K\left(t_{i}, t_{i}\right) u_{i}+\frac{h_{i}}{4} K\left(t_{i}, t_{i-1}\right) u_{i-1} \\
& +\widetilde{K}\left(t_{0}, \ldots t_{i-1} ; u_{0}, \ldots, u_{i-1}\right)+R_{i},=f_{i}, \quad i=1(1) N
\end{aligned}
$$

where

$\widetilde{K}\left(t_{0}, \ldots t_{i-1} ; u_{0}, \ldots, u_{i-1}\right)=\left\{\begin{array}{lr}0, & i=1, \\ \sum_{j=1}^{i-1} \frac{h_{j}}{2}\left[K\left(t_{i}, t_{j}\right) u_{j}+K\left(t_{i}, t_{j-1}\right) u_{j-1}\right], & i>1,\end{array}\right.$

and the discretization error is

$$
\begin{aligned}
R_{i}= & -h_{i}^{-1} \int_{t_{i-1}}^{t_{i}}\left(t-t_{i-1}\right) \frac{d}{d t}[a(t) u(t)-f(t)] d t \\
& -h_{i}^{-1} \int_{t_{i-1}}^{t_{i}}\left(t-t_{i-1}\right) \frac{d}{d t}\left[\int_{0}^{t} K(t, s) u(s) d s\right] d t \\
& +\sum_{j=1}^{i} \int_{t_{j-1}}^{t_{j}}\left(t_{j}-s\right) \frac{d}{d s}\left[K\left(t_{i}, s\right) u(s)\right] d s
\end{aligned}
$$

Neglecting the remainder term in (2.11), we suggest the following fitted mesh finite difference scheme to approximate the solution of (1.1)-(1.2)

$$
\begin{gathered}
L^{N} y_{i} \equiv \varepsilon y_{\tilde{t}, i}+a_{i} y_{i}+\frac{h_{i}}{4} K\left(t_{i}, t_{i}\right) y_{i}+\frac{h_{i}}{4} K\left(t_{i}, t_{i-1}\right) y_{i-1}+ \\
\widetilde{K}\left(t_{0}, \ldots t_{i-1} ; y_{0}, \ldots, y_{i-1}\right)=f_{i}, \quad i=1(1) N, \\
y_{0}=\gamma_{0},
\end{gathered}
$$

where

$\widetilde{K}\left(t_{0}, \ldots t_{i-1} ; y_{0}, \ldots, y_{i-1}\right)=\left\{\begin{array}{lr}0, & i=1, \\ \sum_{j=1}^{i-1} \frac{h_{j}}{2}\left[K\left(t_{i}, t_{j}\right) y_{j}+K\left(t_{i}, t_{j-1}\right) y_{j-1}\right], & i>1 .\end{array}\right.$

The lower triangular system of linear equations (1.1)-(1.2) takes the form

$$
A U=F,
$$

where the various entries of the matrix $A$ and components of the column-vector $F$ are given by

$A_{i i}=r_{i}^{c}, \quad i=1(1) N$,

$A_{i, i-1}=r_{i, i-1}^{-} \quad i=2(1) N$

$A_{i, j}=r_{i, i-1}^{-} \quad i=3(1) N ; j=1(1) i-1$,

$F_{1}=f_{1}-\left(-\frac{\varepsilon}{h_{1}}+\frac{h_{1}}{4} K K_{1}\right) y_{0} \quad i=1$,

$F_{i}=f_{i}-\left(\frac{h_{1}}{2} K K_{i}\right) y_{0} \quad i=2(1) N$,

where

$K K=K_{i 0}$,

$r_{i}^{c}=\left(\frac{\varepsilon}{h_{i}}\right)+a_{i}+\frac{h_{i}}{4} K_{i i}$,

$r_{i, i-1}^{-}=\left(\frac{-\varepsilon}{h_{i}}\right)+\frac{h_{i}}{4} K_{i, i-1}+\frac{1}{2} h_{i-1} K_{i, i-1}$,

$r_{i, i-1}^{-}=\left(\frac{h_{j}+h_{j-1}}{2}\right) K_{i, j}$.

Here we refer to this scheme as FMFDM. The discrete operator in the Fitted Mesh Finite Difference Method, which we denote by $l^{N}$, satisfies the following lemmas [2]. 
Lemma 21Let the difference operator

$l^{N} y_{i}=V_{i} y_{i}-W_{i} y_{i-1}, \quad 1 \leq i \leq N$,

be given, where $V_{i}>0$ and $W_{i}>0$. Then, for all mesh function $\Phi_{i}$ such that $\Phi_{0} \geq 0, l^{N} \Phi_{i} \geq 0$ for all $i \geq 1$, we have $\Phi_{i} \geq 0$ for all $0 \leq i \leq N$

\section{Proof}

Assume that $\Phi_{k} \leq 0$ for some $k$ satisfying $0 \leq k \leq N$ and that $\Phi_{k}=\min _{0 \leq i \leq N} \Phi_{i}$. Then we have $\Phi_{k}-\Phi_{k-1} \leq 0$ and so $l^{N} \Phi_{k} \equiv V_{i} \Phi_{k}-W_{i} \Phi_{k-1}<0$, which contradicts the hypothesis of the lemma. Hence $\Phi_{k} \geq 0$ and for all $i$, $\Phi_{i} \geq 0,1 \leq i \leq N$. This discrete principal which guarantees the uniqueness of the solution enables us to prove the following lemma which provides the boundedness of the the solution.

Lemma 22Let $l^{N} y_{i}$ be difined as in (2.16). If $V_{i}-W_{i} \geq$ $\alpha>0$, then for the solution of the difference initial value problem

$l^{N} y_{i}=F_{i}, \quad i \geq 1$,

$y_{0}=\mu$

the following inequality holds

$\|y\|_{\infty} \leq|\mu|+\alpha^{-1} \max _{0 \leq i \leq N}\left|F_{i}\right|$

\section{Proof}

Consider two mesh functions which we define by

$\Pi_{i}=|\beta|+\alpha^{-1} \max _{0 \leq i \leq N}\left|\Phi_{i}\right| \pm y_{i}$

It is easy to see that

$$
\Pi \geq 0
$$

and taht for $i \geq 1$,

$$
\begin{aligned}
l^{N} \Pi_{i}= & A_{i}\left[|\mu|+\frac{1}{\alpha} \max _{0 \leq i \leq N}\left|F_{i}\right|+\left( \pm y_{i}\right)\right] \\
& -B_{i}\left[|\mu|+\frac{1}{\alpha} \max _{0 \leq i \leq N}\left|F_{i-1} \pm y_{i-1}\right|\right] \\
= & \left(A_{i}-B_{i}\right)|\mu|+\frac{1}{\alpha}\left[A_{i} \max _{0 \leq i \leq N}\left|F_{i}\right|-B_{i} \max _{0 \leq i \leq N}\left|F_{i-1}\right|\right] \pm F_{i} \\
\geq & \left(A_{i}-B_{i}\right)|\mu|+\frac{1}{\alpha}\left[A_{i} \max _{0 \leq i \leq N}\left|F_{i}\right|-B_{i} \max _{0 \leq i \leq N}\left|F_{i}\right|\right] \pm F_{i} \\
\geq & \left(A_{i}-B_{i}\right)|\mu|+\frac{A_{i}-B_{i}}{\alpha} \max _{0 \leq i \leq N}\left|F_{i}\right| \pm F_{i} \geq 0 \\
\geq & 0 .
\end{aligned}
$$

Applying the dicrete maximum principle (Lemma 21) we can conclude that $\Pi_{i} \geq 0, \forall i$ thus

$\|y\|_{\infty} \leq|\beta|+\alpha^{-1} \max _{0 \leq i \leq N}\left|F_{i}\right|$

which is the required result.

Lemma 23Assume that

$\alpha+\frac{h_{i}}{4} K_{i i} \geq \alpha_{*}>0, \quad i=1(1) N$.
Then for the difference operator

$l^{N} v_{i}=\varepsilon v_{\tilde{t}, i}+a_{i} v_{i}+\frac{h_{i}}{4} K_{i i} v_{i}$

where $K_{i i}=K\left(t_{i}, t_{i}\right)$ we have

$\left\|v_{i}\right\|_{\infty} \leq\left|v_{0}\right|+\alpha \max _{0 \leq i \leq N}\left|l^{N} v_{i}\right|$

Proof

The difference expression (2.20) can be rewritten as

$l^{N} y_{i} \equiv V_{i} y_{i}-W_{i} y_{i-1}$.

where

$V_{i}=\frac{\varepsilon}{h_{i}}+a_{i}+\frac{h_{i}}{2} K\left(t_{i}, t_{i}\right)>0$,

and

$W_{i}=\frac{\varepsilon}{h_{i}}>0$,

since

$V_{i}-W_{i}=a_{i}+\frac{h_{i}}{2} K\left(t_{i}, t_{i}\right)>0 \quad$ by $\quad(2.19)$,

and (2.21) follows in virtue of (2.17).

Lemma 24(Stability for the difference problem (2.13)-(2.14)). Let the difference operator $l^{N} y_{i}$ be given by (2.20). Then for the difference problem (2.13)-(2.14) we get

$l^{N} y_{i} \leq C \sum_{j=1}^{i} h_{j}\left|y_{j-1}\right|+\|f\|_{\infty}, \quad 1 \leq i \leq N$.

\section{Proof}

From (2.13) we have

$\left|l^{N} y_{i}\right| \leq\left|f_{i}\right|+\left|\sum_{j=1}^{i-1} \frac{h_{j}}{2} K\left(t_{i}, t_{j}\right) y_{j}\right|+\left|\sum_{j=1}^{i} \frac{h_{j}}{2} K\left(t_{i}, t_{j-1}\right) y_{j-1}\right|$.

Taking into account the fact that the kernel is bounded, this clearly leads to (2.23).

Lemma 25Let (2.19) be satisfied, then for the solution of the difference scheme (2.13)-(2.14) we have the following estimate

$\left|y_{i}\right| \leq\left(\alpha_{*}^{-1}|| f \|_{\infty}+|A|\right) \exp \left(\alpha_{*}^{-1} C t_{i}\right), \quad 1 \leq i \leq N$.

See Lemma 4.4 of [2]

\subsection{Error analysis of the FMFDM}

Let $\tau_{i}=y_{i}-u_{i}, 0 \leq i \leq N$, where $y_{i}$ is the solution of (2.13)-(2.14) and $u_{i}$ the solution of (1.1)-(1.2) at the mesh point $t_{i}$. Then for the error function $\tau_{i}$, we have

$\begin{aligned} L^{N} \tau_{i}= & \varepsilon \tau_{\tilde{t}, i}+\left[a_{i} y_{i}-a_{i} u_{i}\right]+\frac{h_{i}}{4}\left[K\left(t_{i}, t_{i}\right) y_{i}-K\left(t_{i}, t_{i}\right) u_{i}\right]+ \\ & \frac{h_{i}}{4}\left[K\left(t_{i}, t_{i-1}\right) y_{i-1}-K\left(t_{i}, t_{i-1}\right) u_{i-1}\right]+\widetilde{K}+R_{i} \quad i=1(1) N,\end{aligned}$

$\tau_{0}=0$, 
where the remainder term $R_{i}$ is given by (2.12) and

$$
\widetilde{K}= \begin{cases}0, & \text { for } i=1, \\ \sum_{j=1}^{i} \frac{h_{j}}{2}\left\{\left[K\left(t_{i}, t_{j}\right) y_{j}-K\left(t_{i}, t_{j}\right) u_{j}\right],\right. & \\ \left.+\left[K\left(t_{i}, t_{j-1}\right) y_{j-1}-K\left(t_{i}, t_{j-1}\right) u_{j-1}\right]\right\} & \text { for } i>1 .\end{cases}
$$

Lemma 26Under the requirements of Lemma 11, for the remainder term $R_{i}$ of the scheme (2.13)-(2.14) the following inequality

$$
\left\|R_{i}\right\|_{\infty, \psi_{N}} \leq C N^{-1}
$$

holds.

\section{Proof}

We rewrite the remainder term in the form

$R_{i}=R_{i}^{(1)}+R_{i}^{(2)}+R_{i}^{(3)}$

where $R_{i}^{(1)}, R_{i}^{(2)}$ and $R_{i}^{(3)}$ are respectively given by (2.7), (2.8) and (2.10). From (2.7), taking into consideration the hypothesis of Lemma 11 on an arbitrary mesh we get

$$
\begin{aligned}
\left|R_{i}^{(1)}\right| & \leq C\left\{h_{i}+\int_{t_{i-1}}^{t_{i}}\left|u^{\prime}(t)\right| d t\right\}, \quad i=1(1) N \\
& \leq C\left\{h_{i}+\frac{1}{\varepsilon} \int_{t_{i-1}}^{t_{i}} \exp (-\alpha t / \varepsilon) d t\right\}, \quad i=1(1) N .
\end{aligned}
$$

For (2.8), using Leibnitz rule and (1.3) we obtain

$$
\begin{aligned}
\left|R_{i}^{(2)}\right| \leq & h_{i}^{-1} \int_{t_{i-1}}^{t_{i}}\left(t-t_{i-1}\right)\left|\frac{\partial}{\partial t} \int_{0}^{t} K(t, s) u(s) d s\right| d t \\
\leq & h_{i}^{-1} \int_{t_{i-1}}^{t_{i}}\left(t-t_{i-1}\right)|K(t, t)||u(t)| d t \\
& \quad-h_{i}^{-1} \int_{t_{i-1}}^{t_{i}}\left(t-t_{i-1}\right)\left|\int_{0}^{t} \frac{\partial}{\partial t} K(t, s) u(s) d s\right| d t \\
\leq & C h_{i}, \quad i=1(1) N .
\end{aligned}
$$

Lastly from (2.10),

$$
\begin{aligned}
\left|R_{i}^{(3)}\right|= & \left|\sum_{j=1}^{i} \int_{t_{j-1}}^{t_{j}}\left(t_{j}-s\right) \frac{d}{d s}\left[K\left(t_{i}, s\right) u(s)\right] d s\right| \\
\leq & \left|\sum_{j=1}^{i} \int_{t_{j-1}}^{t_{j}}\left(t_{j}-s\right) \frac{\partial}{\partial t} K\left(t_{i}, s\right) u(s) d s\right| \\
& +\left|\sum_{j=1}^{i} \int_{t_{j-1}}^{t_{j}}\left(t_{j}-s\right) K\left(t_{i}, s\right) u(s) d s\right|, \\
\leq & C h_{i}\left[\int_{0}^{t_{i}}|u(s)| d s+\int_{0}^{t_{i}}\left|u^{\prime}(s)\right| d s\right]
\end{aligned}
$$

Further, since, by (1.3) $\int_{0}^{t_{i}}\left|u^{\prime}(s)\right| d t \leq C$ we have

$$
\left|R_{i}^{(3)}\right| \leq C h_{i} \quad i=1(1) N
$$

In each of the subdomains $[0, \lambda]$ and $[\lambda, 1]$, we estimate the remainder $R_{i}$ as following.
In the subdomain $[0, \lambda]$, considering the estimate 11 we have from (2.28) that

$$
\begin{array}{r}
\left|R_{i}^{(-1)}\right| \leq C\left[h_{i}+\alpha^{-1}\left(\exp \left(-\frac{\alpha t_{i-1}}{\varepsilon}\right)+\exp \left(-\frac{\alpha t_{i}}{\varepsilon}\right)\right)\right], \\
i=1(1) N .
\end{array}
$$

and,

$$
\begin{aligned}
h_{i}= & -\alpha^{-1} \varepsilon \ln \left[1-(1-\varepsilon) \frac{2 i}{N}\right] \\
& +\alpha^{-1} \varepsilon \ln \left[1-(1-\varepsilon) \frac{(2(i-1))}{N}\right] \\
\leq & 2 \alpha^{-1}(\varepsilon-1) N^{-1} .
\end{aligned}
$$

But also,

$$
\exp \left(-\alpha t_{i-1} / \varepsilon\right)+\exp \left(-\alpha t_{i} / \varepsilon\right)=2(1-\varepsilon) N^{-1}
$$

It follows from (2.31) that

$\left|R_{i}^{(-1)}\right| \leq C N^{-1}, \quad i=1(1) N / 2$.

For (2.29) and (2.30) we get the following approximation

$\left|R_{i}^{(2)}\right| \leq C N^{-1}, \quad i=1(1) N / 2$.

$\left|R_{i}^{(3)}\right| \leq C N^{-1}, \quad i=1(1) N / 2$.

As a result, from (2.32)-(2.34) for the subdomain $[0, \lambda]$ we obtain the estimate

$\left|R_{i}\right| \leq C N^{-1}, \quad i=1(1) N / 2$.

Next, consider $[\lambda, 1]$ and recall [16] that

$u^{\prime}(t) \leq C$ or $\varepsilon^{-1} \exp (-\alpha t / \varepsilon) \leq 1 \quad$ which implies that

$\left|R_{i}^{(1)}\right| \leq C h, \quad i=N / 2+1(1) N$.

In the similar manner as above, we obtain

$\left|R_{i}^{(1)}\right| \leq C N^{-1}, \quad i=N / 2+1(1) N$.

$\left|R_{i}^{(2)}\right| \leq C N^{-1}, \quad i=N / 2+1(1) N$,

$\left|R_{i}^{(3)}\right| \leq C N^{-1}, \quad i=N / 2+1(1) N$.

From (2.37)-(2.39) for the subdomain $[\lambda, 1]$ we obtain

$\left|R_{i}\right| \leq C N^{-1} \quad i=N / 2+1(1) N$.

And this completes the proof.

Lemma 27Let (2.19) be satisfied, then the solution $\tau_{i}$ of the problem (2.25)-(2.26) satisfies

$\left\|\tau_{i}\right\|_{\infty, \psi_{N}} \leq \max _{0 \leq i \leq N}\left|R_{i}\right|$

Proof

The proof is a traight result of (2.24) by putting $A=0$ and $F=R$. The results of Lemmas 26 and 2.2 are now combined to give the following main estimate in this section 
Theorem 28 Let $u$ be the solution of the continuous problem (1.1)-(1.2) and $y$ the solution of the discrete problem (2.13)-(2.14). Then under the requirements of Lemma 11, we have

$$
\|y-u\|_{\infty, \psi_{N}} \leq C N^{-1}
$$

Remark 29Note that the above $\varepsilon$-uniform result does not contain the so called "locking factor" which usually surfaces when discretisations are made on Shishkin meshes. If fact, estimates of the type $\|y-u\|_{\infty, \psi_{N}} \leq C N^{-1} \ln N$ are encountered when the choice of the transition point is dependent on some factor of $\ln N$. Our choice of the transition point was inspired by [16] which uses a factor of $\ln \varepsilon$ (See (2.4)).

\section{Method II: EFOFDM}

In this section the mesh is taken to be uniform. As before, let $N$ be a positive integer. We consider the following uniform partition of the interval $[0,1]$ which we denote by $\bar{\psi}^{N}$ :

$t_{0}=0, \quad t_{i}=t_{0}+i h, \quad i=1(1) N, t_{N}=1$ where $h=1 / N$, the mesh size. In the rest of the section, we first construct the numerical method and derive the fitting factor. Then we give some useful facts of the scheme and finaly we carry out the convergence analysis.

\subsection{Derivation of the scheme}

To get started, we recall that the problem discussed in the previous section is considered again here. In [2], Amiraliyev and Şevgin suggested a EFOFDM to solve (1.1)-(1.2). Our aim in this section is to constructed a modified EFOFDM for (1.1)-(1.2) which is based on the underlying idea of EFOFDM in [2]. To achieve the goal, we consider the following identity[2]

$\chi_{i}^{-1} h^{-1} \int_{t_{i-1}}^{t_{1}} \operatorname{Lu} \varphi_{i}(t) d t=\chi^{-1} h^{-1} \int_{t_{i-1}}^{t_{i}} f(t) \varphi_{i}(t) d t$,

where the exponential function $\varphi_{i}(t)$ and $\chi_{i}$ are the slight variants of the ones from [2] and hence are respectively given by

$\varphi_{i}(t)=\exp \left(\frac{a_{i}}{\varepsilon}\left(t-t_{i}\right)\right)$,

$$
\chi_{i}=h^{-1} \int_{t_{i-1}}^{t_{i}} \varphi_{i}(t) d t=\frac{1-\exp \left(-\rho a_{i}\right)}{\rho a_{i}} \text { with } \rho=h / \varepsilon .
$$

We note that the exponential basis function $\varphi_{i}(t)$ satisfies

$-\varepsilon \varphi_{i}^{\prime}(t)+a_{i} \varphi_{i}(t)=0, \quad \varphi\left(t_{i}\right)=1$,

and that

$\chi_{i}^{-1} h^{-1} \int_{t_{i-1}}^{t_{i}} \varphi_{i}(t) d t=1$.
Hence, relation (3.43) is written in the form

$$
\begin{gathered}
\chi_{i}^{-1} h^{-1} \varepsilon \int_{t_{i-1}}^{t_{i}} u^{\prime}(t) \varphi_{i}(t) d t+\chi_{i}^{-1} h^{-1} a_{i} \int_{t_{i-1}}^{t_{i}} u(t) \varphi_{i}(t) d t+ \\
\chi_{i}^{-1} h^{-1} \int_{t_{i-1}}^{t_{i}} \varphi_{i}(t)\left(\int_{0}^{t} K(t, s) u(s) d s\right) d t=f_{i}-R_{i}^{(1)},
\end{gathered}
$$

where

$$
\begin{aligned}
R_{i}^{(1)}= & \chi_{i}^{-1} h^{-1} \int_{t_{i-1}}^{t_{1}}\left[a(t)-a\left(t_{i}\right)\right] u(t) \varphi_{i}(t) d t \\
& +\chi_{i}^{-1} h^{-1} \int_{t i-1}^{t_{i}}\left[f\left(t_{i}\right)-f(t)\right] \varphi_{i}(t) d t .
\end{aligned}
$$

Utilizing quadrature rules (2.1) and (2.2) from [4] for $\sigma=1$ on the interval $\left[t_{i}-t_{i-1}\right]$ and take into considerartion (3.46) we have the following expression

$$
\begin{aligned}
& \chi_{i}^{-1} h^{-1} \varepsilon \int_{t_{i-1}}^{t_{i}} u^{\prime}(t) \varphi_{i}(t) d t+\chi_{i}^{-1} h^{-1} a_{i} \int_{t_{i-}}^{t_{i}} u(t) \varphi_{i}(t) d t+ \\
& \chi_{i}^{-1} h^{-1} \int_{t_{i-1}}^{t_{i}} \varphi_{i}(t)\left(\int_{0}^{t} K(t, s) u(s) d s\right) d t=f_{i}-R_{i}^{(1)} \\
= & \varepsilon u_{\tilde{t}, i}\left[\chi_{i}^{-1} h^{-1} \int_{t_{i-1}}^{t_{i}} \varphi_{i}(t) d t+\chi_{i}^{-1} h^{-1} a_{i} \int_{t_{i-1}}^{t i}\left(t-t_{i}\right) \varphi_{i}(t) d t\right] \\
& +a_{i} u_{i}+\chi_{i}^{-1} h^{-1} \int_{t_{i-1}}^{t_{i}} \varphi_{i}(t) d t \int_{0}^{t_{i}} K\left(t_{i}, s\right) u(s) d s+ \\
& +\int_{t_{i-1}}^{t_{i}} \frac{d}{d \eta}\left[\int_{0}^{\eta} K(\eta, s) u(s) d s\right][H(T-\eta)-1] d \eta \\
= & \varepsilon \theta_{i} u_{\tilde{t}, i}+a_{i} u_{i}+\int_{0}^{t_{i}} K\left(t_{i}, s\right) u(s) d s+\chi_{i}^{-1} h^{-1} \int_{t_{i-1}}^{t_{i}} \varphi_{i}(t) d t \times \\
& \int_{t_{i-1}}^{t_{i}} \frac{d}{d \eta}\left[\int_{0}^{\eta} K(\eta, s) u(s) d s\right][H(T-\eta)-1] d \eta
\end{aligned}
$$

where $\theta_{i}=1+\chi_{i}^{-1} h^{-1} a_{i} \int_{t_{i-1}}^{t i}\left(t-t_{i}\right) \varphi_{i}(t) d t, H(T-\eta)$ is a Heaviside function. Moroever, applying the repeated trapezoidal integration to the integral in the last expression:

$\int_{0}^{t_{i}} K\left(t_{i}, s\right) u(s) d s$

we get the following expression for $u\left(t_{i}\right)$

$$
\begin{aligned}
& \varepsilon \theta_{i} u_{\tilde{t}, i}+a_{i} u_{i}+\frac{h}{4} K\left(t_{i}, t_{i}\right) u_{i}+\frac{h}{4} K\left(t_{i}, t_{i-1}\right) u_{i-1}+ \\
& \frac{h}{2} \widetilde{K}\left(t_{0}, \ldots t_{i-1} ; u_{0}, \ldots, u_{i-1}\right)+R_{i}=f_{i}, \quad i=1(1) N, \\
& \text { where } \\
& R_{i}=-\chi_{i}^{-1} h^{-1} \int_{t_{i-1}}^{t_{1}}\left[a(t)-a\left(t_{i}\right)\right] u(t) \varphi_{i}(t) d t \\
& +\chi_{i}^{-1} h^{-1} \int_{t i-1}^{t_{i}}\left[f\left(t_{i}\right)-f(t)\right] \varphi_{i}(t) d t \\
& +\int_{t_{i-1}}^{t_{i}} \frac{d}{d \eta}\left[\int_{0}^{\eta} K(\eta, s) u(s) d s\right][H(T-\eta)-1] d \eta \\
& +\sum_{j=1}^{i} \int_{t_{j-1}}^{t_{j}}\left(t_{j}-\eta\right) \frac{d}{d s}\left[K\left(t_{i}, \eta\right) u(\eta)\right] d \eta
\end{aligned}
$$


and

$\widetilde{K}\left(t_{0}, \ldots, t_{i-1} ; u_{0}, \ldots, u_{i-1}\right)= \begin{cases}0, & i=1, \\ \sum_{j=1}^{i-1}\left[K\left(t_{i}, t_{j}\right) u_{j}+K\left(t_{i}, t_{j-1}\right) u_{j-1}\right], & i>1 .\end{cases}$

A simple algebra shows that

$\theta_{i}=\frac{\rho a_{i} \exp \left(\rho a_{i}\right)}{\left(1-\exp \left(-\rho a_{i}\right)\right)}$.

Neglecting $R_{i}$ in (3.48) we may propose the following exponential finite difference scheme to approximate (1.1)-(1.2):

$$
\begin{aligned}
L^{h} y_{i} \equiv & \varepsilon \theta_{i} y_{\tilde{t}, i}+a_{i} y_{i}+\frac{h}{4} K\left(t_{i}, t_{i}\right) y_{i}+\frac{h}{4} K\left(t_{i}, t_{i-1}\right) y_{i-1} \\
& +\frac{h}{2} \widetilde{K}\left(t_{0}, \ldots t_{i-1} ; y_{0}, \ldots, y_{i-1}\right)=f_{i}, \quad i=1(1) N,(3.51) \\
y_{0}= & \gamma_{0},
\end{aligned}
$$

where

$\widetilde{K}\left(t_{0}, \ldots t_{i-1} ; y_{0}, \ldots, y_{i-1}\right)= \begin{cases}0 & i=1, \\ \sum_{j=1}^{i-1}\left[K\left(t_{i}, t_{j}\right) y_{j}+K\left(t_{i}, t_{j-1}\right) y_{j-1}\right] & i>1 .\end{cases}$

The lower triangular system of linear equation (1.1)-(1.2) takes the form

$$
A U=F,
$$

$A_{i i}=r_{i}^{c}, \quad i=1(1) N$

$A i, i-1=r_{i, i-1}^{-} \quad i=2(1) N$,

$A i, j=r_{i, i-1}^{-} \quad i=3(1) N ; j=1(1) i-1$,

$F=f_{1}-\left(-\frac{\varepsilon \theta_{1}}{h}+\frac{h}{4} K K_{1}\right) y_{0} \quad i=1$,

$F_{i}=f_{i}-\left(\frac{h}{2} K K_{i}\right) y_{0} \quad i=2(1) N$

where

$r_{i}^{c}=\frac{\varepsilon \theta_{i}}{h}+a_{i}+\frac{h}{4} K_{i i}$,

$\left.\begin{array}{l}r_{i, i-1}^{-}=\frac{-\varepsilon \theta_{i}}{h}+\frac{h}{4} K_{i, i-1}+\frac{1}{2} h K_{i, i-1}, \\ r_{i, i-1}^{-}=\frac{h}{2} K\left(t_{i}, t_{j}\right) .\end{array}\right\}$

\subsection{Some useful properties of the EFOFDM}

Lemma 31Let the difference operator

$l y_{i}=A_{i} y_{i}-B_{i} y_{i-1}, \quad 1 \leq i \leq N$,

be given, where $A_{i}>0$ and $B_{i}>0$. Then the difference operator (3.54) satisfies the following discrete maximum principal: if $l y_{i} \geq 0, \forall i \geq 0$ and $y_{0} \geq 0$, then $y_{i} \geq 0, \forall i \geq 0$.

Proof Following the technique of proof given in Lemma 21 , we can prove the present Lemma

Lemma 32Let $l y_{i}$ be difined as in (3.54). If $A_{i}-B_{i} \geq \alpha>0$, then for the solution of the difference initial value problem

$l y_{i}=F_{i}, \quad i \geq 1$

$y_{0}=\mu$

the following inequality holds

$\left\|y_{i}\right\|_{\infty} \leq|\mu|+\alpha^{-1} \max _{0 \leq i \leq N}\left|F_{i}\right|$
Proof The proof is obtained by arguments similar to those used in proving Lemma 4.1 part 2 and 3

Lemma 33Let the condition

$\alpha+\frac{h}{4} K_{i i} \geq \alpha_{*}>0, \quad i=1(1) N$

be guaranteed, then for the difference operator

$l^{h} v_{i}=\varepsilon \theta_{i} v_{\tilde{t}, i}+a_{i} v_{i}+\frac{h}{4} K_{i i} v_{i}$

we have

$\left\|v_{i}\right\|_{\infty} \leq\left|v_{0}\right|+\alpha \max _{0 \leq i \leq N}\left|l v_{i}\right|$

where $K_{i i}=K\left(t_{i}, t_{i}\right)$.

Proof see (2.1)

Lemma 34[Stability of the discrete problem (3.51)-(3.52)] . Let the difference operator $l^{h} y_{i}$ be defined by (3.57). Then for difference problem (3.51)-(3.52) we have

$l^{h} y_{i} \leq C h \sum_{j=1}^{i}\left|y_{j-1}\right|+\|f\|_{\infty}, \quad 1 \leq i \leq N$

From (2.13) we get

$\left|l^{h} y_{i}\right| \leq\left|f_{i}\right|+\left|\frac{h}{2} \sum_{j=1}^{i-1} K\left(t_{i}, t_{j}\right) y_{j}\right|+\left|\frac{h}{2} \sum_{j=1}^{i} K\left(t_{i}, t_{j-1}\right) u_{j-1}\right|$

and taking into account the fact that the kernel $K(t, s)$ is bounded, (3.59) can be established

Lemma 35Let (3.56) be satisfied, then for then solution of the difference scheme (3.51)-(3.52) we have the following estimate

$\left|y_{i}\right| \leq\left(\alpha_{*}^{-1}|| f \|_{\infty}+|A|\right) \exp \left(\alpha_{*}^{-1} C t_{i}\right), \quad 1 \leq i \leq N$.

\section{Proof}

See [2] Lemma 4.4

\subsection{Error analyis of the EFOFDM}

Let $z_{i}=y_{i}-u_{i}$, where $y_{i}$ and $u_{i}$ are solution of problems (3.51)-(3.52) and (1.1)-(1.2) respectively at the mesh point $t_{i}$. Then for the error function $z_{i}$, we have

$$
\begin{aligned}
L^{h} z_{i} & =R_{i}, \quad i=1(1) N, \\
z_{0} & =0,
\end{aligned}
$$

where $R_{i}$ is defined by (3.49).

Lemma 36Under conditions $a, f \in C^{1}$ and $K \in C_{0}^{1}$, the remainder term (3.49) of the scheme (3.51)-(3.52) satisfies

$\|R\|_{\infty, \psi_{h}} \leq C h$ 
Proof

We rewrite $R_{i}$ as

$$
\begin{aligned}
R_{i}^{(1)}= & -\chi_{i}^{-1} h^{-1} \int_{t_{i-1}}^{t_{1}}\left[a(t)-a\left(t_{i}\right)\right] u(t) \varphi_{i}(t) d t \\
& +\chi_{i}^{-1} h^{-1} \int_{t i-1}^{t_{i}}\left[f\left(t_{i}\right)-f(t)\right] \varphi_{i}(t) d t \\
R_{i}^{(2)}= & \int_{t_{i-1}}^{t_{i}} \frac{d}{d \eta}\left[\int_{0}^{\eta} K(\eta, s) u(s) d s\right][H(T-\eta)-1] d \eta \\
R_{i}^{(3)}= & \sum_{j=1}^{i} \int_{t_{j-1}}^{t_{j}}\left(t_{j}-\eta\right) \frac{d}{d \eta}\left[K\left(t_{i}, \eta\right) u(\eta)\right] d \eta
\end{aligned}
$$

First we prove that for (3.64) inequality

$$
\left|R_{i}^{(1)}\right| \leq C h \quad 1(1) N
$$

holds. We rewrite (3.64) as

$$
\begin{aligned}
\left|R_{i}^{(1)}\right| \leq & \chi_{i}^{-1} h^{-1} \int_{t_{i-1}}^{t_{i}}\left|\left[a(t)-a\left(t_{i}\right)\right] u(t) \varphi_{i}(t)\right| d t \\
& +\chi_{i}^{-1} h^{-1} \int_{t_{i-1}}^{t_{i}}\left|\left[f\left(t_{i}\right)-f(t)\right] \varphi_{i}(t)\right| d t .
\end{aligned}
$$

It follows by means of the intermediate value theorem [2] that

$$
\begin{aligned}
\left|a(t)-a\left(t_{i}\right)\right| & =\left|a^{\prime}\left(\vartheta_{i}\right)\right|\left|t-t_{i}\right| \leq C_{1} h, & & \vartheta_{i} \in\left(t_{i}, t\right), \\
\left|f\left(t_{i}\right)-f(t)\right| & =\left|f^{\prime}\left(v_{i}\right)\right|\left|t_{i}-t\right| \leq C_{2} h, & & v_{i} \in\left(t, t_{i}\right)
\end{aligned}
$$

and so, it is easy to see that (3.67) is true.

Next, for (3.65) we have [2],

$$
\begin{aligned}
R_{i}^{(2)}= & \int_{t_{i-1}}^{t_{i}}\left\{K(\eta, \eta) u \eta+\int_{0}^{\eta} \frac{\partial}{\partial_{\eta}}[K(\eta, s) u(s)] d s\right\} \\
& \times[H(t-\eta)-1] d \eta \\
\leq & C \int_{t_{i-1}}^{t_{i}}\left\{|K(\eta, \eta)||u(\eta)|+\left|\int_{0}^{\eta} \frac{\partial}{\partial_{\eta}} K(\eta, s) u(s) d s\right|\right\} \\
& \times[H(t-\eta)-1] d \eta \\
\leq & C\left\{\int_{t_{i-1}}^{t_{i}}|u(\eta)| d \eta+\int_{t_{i-1}}^{t_{i}}\left|\int_{0}^{\eta} u(s) d s\right| d \eta\right\} .
\end{aligned}
$$

Using Lemma 11 we obtain

$$
R_{i}^{(2)} \leq C h
$$

Following the same lines of discussion as in (2.30), it can be observed that (3.66) satisfies (3.63). This completes the proof.

Lemma 37Let (3.56) be satisfied, then the solution $z_{i}$ of the problem (3.61)-(3.62) satisfies

$\left\|z_{i}\right\|_{\infty, \psi_{h}} \leq \max _{0 \leq i \leq N}\left|R_{i}\right|$.

\section{Proof}

The proof is straight forward as a consequence of (3.60) by setting $A=0$ and $F=R$. Using lemmas 36 and 37, we obtained the following first order $\varepsilon$-uniformly accurate error estimate in the maximum norm which we summarize in the theorem below.
Theorem 38Assume that $u$ satisfies the continous problem (1.1)-(1.2) and y satisfies the descrete problem (3.51)-(3.52). Then under assumptions that $a, f \in C^{1}(I)$ and $K \in C_{0}^{1}$, we have

$\|y-u\|_{\infty, \psi_{h}} \leq C h$

\section{Numerical results}

In the section, we test the two numerical methods described in this paper. To this end, two Volterra integro-differential equations are presented and the maximum errors along with the rates of convergence are given in tabular form. The maximum errors at all the mesh points are evaluated using the formula

$e_{\varepsilon, N}:=\max _{[0 \leq j \leq 1]}\left|u\left(x_{j}\right)-y\left(x_{j}\right)\right|$

for the different values of $N$. The numerical rates of convergence are calculated using the formula

$r_{\varepsilon, k}:=\log _{2}\left(\frac{e_{N_{k, \varepsilon}}}{e_{2 N_{k, \varepsilon}}}\right), k=1,2,3, \ldots$

The test examples are considered over the interval $I=[0,1]$.

Example 41[18] Consider problem (1.1)-(1.2) where the coefficient functions are given by

$$
\begin{aligned}
a(t)= & t+1, K(t, s)=t+s, \\
f(t)= & \varepsilon \cos t+t \sin t+2 \sin t+\left(t-2 t \varepsilon+\varepsilon^{2}\right) \exp \left(\frac{-t}{\varepsilon}\right) \\
& +t-2 t \cos t+\varepsilon t-\varepsilon^{2}, \\
u(0)= & 1 .
\end{aligned}
$$

The exact solution to this problem is given by

$u(t)=\sin t+\exp \left(\frac{-t}{\varepsilon}\right)$.

Example 42[2] Consider problem (1.1)-(1.2) with

$$
\begin{aligned}
a(t)= & 1, K(t, s)=s, \\
f(t)= & \left(2+9 \varepsilon+\varepsilon t+11 t+t^{2}\right) \exp (-t) \\
& -10\left(\varepsilon t+\varepsilon^{2}\right) \exp \left(\frac{-t}{\varepsilon}\right)+5 t^{2}+10 \varepsilon^{2}-2, \\
u(0)= & 10 .
\end{aligned}
$$

The exact solution to this problem is given by

$$
u(t)=10-(10+t) \exp (-t)+10 \exp \left(\frac{-t}{\varepsilon}\right)
$$


Table 1: Results for Example 41: Maximum pointwise error EFOFDM

\begin{tabular}{|c|ccccccc|}
\hline$\varepsilon$ & $N=40$ & $N=80$ & $N=160$ & $N=320$ & $N=640$ & $N=1280$ & $N=2560$ \\
\hline $10^{-2}$ & $3.24 \mathrm{E}-02$ & $1.62 \mathrm{E}-02$ & $8.13 \mathrm{E}-03$ & $4.07 \mathrm{E}-03$ & $2.03 \mathrm{E}-03$ & $1.02 \mathrm{E}-03$ & $5.08 \mathrm{E}-04$ \\
$10^{-3}$ & $3.24 \mathrm{E}-02$ & $1.63 \mathrm{E}-02$ & $8.13 \mathrm{E}-03$ & $4.07 \mathrm{E}-03$ & $2.04 \mathrm{E}-03$ & $1.02 \mathrm{E}-03$ & $5.09 \mathrm{E}-04$ \\
$10^{-4}$ & $3.24 \mathrm{E}-02$ & $1.63 \mathrm{E}-02$ & $8.13 \mathrm{E}-03$ & $4.07 \mathrm{E}-03$ & $2.04 \mathrm{E}-03$ & $1.02 \mathrm{E}-03$ & $5.09 \mathrm{E}-04$ \\
$10^{-5}$ & $3.24 \mathrm{E}-02$ & $1.63 \mathrm{E}-02$ & $8.13 \mathrm{E}-03$ & $4.07 \mathrm{E}-03$ & $2.04 \mathrm{E}-03$ & $1.02 \mathrm{E}-03$ & $5.09 \mathrm{E}-04$ \\
$10^{-6}$ & $3.24 \mathrm{E}-02$ & $1.63 \mathrm{E}-02$ & $8.13 \mathrm{E}-03$ & $4.07 \mathrm{E}-03$ & $2.04 \mathrm{E}-03$ & $1.02 \mathrm{E}-03$ & $5.09 \mathrm{E}-04$ \\
$10^{-7}$ & $3.24 \mathrm{E}-02$ & $1.63 \mathrm{E}-02$ & $8.13 \mathrm{E}-03$ & $4.07 \mathrm{E}-03$ & $2.04 \mathrm{E}-03$ & $1.02 \mathrm{E}-03$ & $5.09 \mathrm{E}-04$ \\
$10^{-8}$ & $3.24 \mathrm{E}-02$ & $1.63 \mathrm{E}-02$ & $8.13 \mathrm{E}-03$ & $4.07 \mathrm{E}-03$ & $2.04 \mathrm{E}-03$ & $1.02 \mathrm{E}-03$ & $5.09 \mathrm{E}-04$ \\
$10^{-9}$ & $3.24 \mathrm{E}-02$ & $1.63 \mathrm{E}-02$ & $8.13 \mathrm{E}-03$ & $4.07 \mathrm{E}-03$ & $2.04 \mathrm{E}-03$ & $1.02 \mathrm{E}-03$ & $5.09 \mathrm{E}-04$ \\
$10^{-10}$ & $3.24 \mathrm{E}-02$ & $1.63 \mathrm{E}-02$ & $8.13 \mathrm{E}-03$ & $4.07 \mathrm{E}-03$ & $2.04 \mathrm{E}-03$ & $1.02 \mathrm{E}-03$ & $5.09 \mathrm{E}-04$ \\
$10^{-11}$ & $3.24 \mathrm{E}-02$ & $1.63 \mathrm{E}-02$ & $8.13 \mathrm{E}-03$ & $4.07 \mathrm{E}-03$ & $2.04 \mathrm{E}-03$ & $1.02 \mathrm{E}-03$ & $5.09 \mathrm{E}-04$ \\
$10^{-12}$ & $3.24 \mathrm{E}-02$ & $1.63 \mathrm{E}-02$ & $8.13 \mathrm{E}-03$ & $4.07 \mathrm{E}-03$ & $2.04 \mathrm{E}-03$ & $1.02 \mathrm{E}-03$ & $5.09 \mathrm{E}-04$ \\
\hline
\end{tabular}

Table 2: Results for Example 41: Maximum pointwise errors FMFDM

\begin{tabular}{|c|ccccccc|}
\hline$\varepsilon$ & $N=40$ & $N=80$ & $N=160$ & $N=320$ & $N=640$ & $N=1280$ & $N=2560$ \\
\hline $10^{-2}$ & $5.96 \mathrm{E}-02$ & $7.83 \mathrm{E}-02$ & $6.75 \mathrm{E}-02$ & $3.95 \mathrm{E}-02$ & $2.20 \mathrm{E}-02$ & $1.17 \mathrm{E}-02$ & $5.97 \mathrm{E}-03$ \\
$10^{-3}$ & $5.85 \mathrm{E}-02$ & $2.93 \mathrm{E}-02$ & $1.49 \mathrm{E}-02$ & $4.30 \mathrm{E}-02$ & $6.82 \mathrm{E}-02$ & $6.32 \mathrm{E}-02$ & $3.69 \mathrm{E}-02$ \\
$10^{-4}$ & $5.80 \mathrm{E}-02$ & $2.91 \mathrm{E}-02$ & $1.46 \mathrm{E}-02$ & $7.28 \mathrm{E}-03$ & $5.25 \mathrm{E}-03$ & $1.46 \mathrm{E}-02$ & $2.94 \mathrm{E}-02$ \\
$10^{-5}$ & $5.76 \mathrm{E}-02$ & $2.89 \mathrm{E}-02$ & $1.45 \mathrm{E}-02$ & $7.23 \mathrm{E}-03$ & $3.62 \mathrm{E}-03$ & $1.81 \mathrm{E}-03$ & $1.75 \mathrm{E}-03$ \\
$10^{-6}$ & $5.73 \mathrm{E}-02$ & $2.87 \mathrm{E}-02$ & $1.44 \mathrm{E}-02$ & $7.20 \mathrm{E}-03$ & $3.60 \mathrm{E}-03$ & $1.80 \mathrm{E}-03$ & $9.01 \mathrm{E}-04$ \\
$10^{-7}$ & $5.70 \mathrm{E}-02$ & $2.86 \mathrm{E}-02$ & $1.43 \mathrm{E}-02$ & $7.17 \mathrm{E}-03$ & $3.59 \mathrm{E}-03$ & $1.79 \mathrm{E}-03$ & $8.97 \mathrm{E}-04$ \\
$10^{-8}$ & $5.69 \mathrm{E}-02$ & $2.85 \mathrm{E}-02$ & $1.43 \mathrm{E}-02$ & $7.15 \mathrm{E}-03$ & $3.58 \mathrm{E}-03$ & $1.79 \mathrm{E}-03$ & $8.95 \mathrm{E}-04$ \\
$10^{-9}$ & $5.67 \mathrm{E}-02$ & $2.85 \mathrm{E}-02$ & $1.43 \mathrm{E}-02$ & $7.14 \mathrm{E}-03$ & $3.57 \mathrm{E}-03$ & $1.79 \mathrm{E}-03$ & $8.93 \mathrm{E}-04$ \\
$10^{-10}$ & $5.66 \mathrm{E}-02$ & $2.84 \mathrm{E}-02$ & $1.42 \mathrm{E}-02$ & $7.13 \mathrm{E}-03$ & $3.57 \mathrm{E}-03$ & $1.78 \mathrm{E}-03$ & $8.92 \mathrm{E}-04$ \\
$10^{-11}$ & $5.66 \mathrm{E}-02$ & $2.84 \mathrm{E}-02$ & $1.42 \mathrm{E}-02$ & $7.12 \mathrm{E}-03$ & $3.56 \mathrm{E}-03$ & $1.78 \mathrm{E}-03$ & $8.91 \mathrm{E}-04$ \\
$10^{-12}$ & $5.65 \mathrm{E}-02$ & $2.84 \mathrm{E}-02$ & $1.42 \mathrm{E}-02$ & $7.11 \mathrm{E}-03$ & $3.56 \mathrm{E}-03$ & $1.78 \mathrm{E}-03$ & $8.90 \mathrm{E}-04$ \\
\hline
\end{tabular}

Table 3: Rates of convergence obtained for Example 41 utilizing EFOFDM

\begin{tabular}{|c|cccccc|}
\hline$\varepsilon$ & $\mathrm{r}=1$ & $\mathrm{r}=2$ & $\mathrm{r}=3$ & $\mathrm{r}=4$ & $\mathrm{r}=5$ & $\mathrm{r}=6$ \\
\hline $10^{-2}$ & 1.00 & 1.00 & 1.00 & 1.00 & 1.00 & 1.00 \\
$10^{-3}$ & 1.00 & 1.00 & 1.00 & 1.00 & 1.00 & 1.00 \\
$10^{-4}$ & 1.00 & 1.00 & 1.00 & 1.00 & 1.00 & 1.00 \\
$10^{-5}$ & 1.00 & 1.00 & 1.00 & 1.00 & 1.00 & 1.00 \\
$10^{-6}$ & 1.00 & 1.00 & 1.00 & 1.00 & 1.00 & 1.00 \\
$10^{-7}$ & 1.00 & 1.00 & 1.00 & 1.00 & 1.00 & 1.00 \\
$10^{-8}$ & 1.00 & 1.00 & 1.00 & 1.00 & 1.00 & 1.00 \\
$10^{-9}$ & 1.00 & 1.00 & 1.00 & 1.00 & 1.00 & 1.00 \\
$10^{-10}$ & 1.00 & 1.00 & 1.00 & 1.00 & 1.00 & 1.00 \\
$10^{-11}$ & 1.00 & 1.00 & 1.00 & 1.00 & 1.00 & 1.00 \\
$10^{-12}$ & 1.00 & 1.00 & 1.00 & 1.00 & 1.00 & 1.00 \\
\hline
\end{tabular}

Table 4: Rates of convergence obtained for Example 42 utilizing FMFDM

\begin{tabular}{|c|cccccc|}
\hline$\varepsilon$ & $\mathrm{r}=1$ & $\mathrm{r}=2$ & $\mathrm{r}=3$ & $\mathrm{r}=4$ & $\mathrm{r}=5$ & $\mathrm{r}=6$ \\
\hline $10^{-2}$ & 1.00 & 1.00 & 1.00 & 1.00 & 1.00 & 1.00 \\
$10^{-3}$ & 1.00 & 1.00 & 1.00 & 1.00 & 1.00 & 1.00 \\
$10^{-4}$ & 1.00 & 1.00 & 1.00 & 1.00 & 1.00 & 1.00 \\
$10^{-5}$ & 1.00 & 1.00 & 1.00 & 1.00 & 1.00 & 1.00 \\
$10^{-6}$ & 1.00 & 1.00 & 1.00 & 1.00 & 1.00 & 1.00 \\
$10^{-7}$ & 1.00 & 1.00 & 1.00 & 1.00 & 1.00 & 1.00 \\
$10^{-8}$ & 0.95 & 0.97 & 0.99 & 0.99 & 1.00 & 1.00 \\
$10^{-9}$ & 0.94 & 0.97 & 0.99 & 0.99 & 1.00 & 1.00 \\
$10^{-10}$ & 0.94 & 0.97 & 0.98 & 0.99 & 1.00 & 1.00 \\
$10^{-11}$ & 0.93 & 0.96 & 0.98 & 0.99 & 1.00 & 1.00 \\
$10^{-12}$ & 0.93 & 0.96 & 0.98 & 0.99 & 1.00 & 1.00 \\
\hline
\end{tabular}

Table 5: Results for Example 42: Maximum pointwise error EFOFDM

\begin{tabular}{|c|ccccccc|}
\hline$\varepsilon$ & $N=40$ & $N=80$ & $N=160$ & $N=320$ & $N=640$ & $N=1280$ & $N=2560$ \\
\hline $10^{-2}$ & $2.23 \mathrm{E}-01$ & $1.12 \mathrm{E}-01$ & $5.61 \mathrm{E}-02$ & $2.81 \mathrm{E}-02$ & $1.40 \mathrm{E}-02$ & $7.02 \mathrm{E}-03$ & $3.51 \mathrm{E}-03$ \\
$10^{-3}$ & $2.23 \mathrm{E}-01$ & $1.12 \mathrm{E}-01$ & $5.61 \mathrm{E}-02$ & $2.81 \mathrm{E}-02$ & $1.41 \mathrm{E}-02$ & $7.03 \mathrm{E}-03$ & $3.52 \mathrm{E}-03$ \\
$10^{-4}$ & $2.23 \mathrm{E}-01$ & $1.12 \mathrm{E}-01$ & $5.61 \mathrm{E}-02$ & $2.81 \mathrm{E}-02$ & $1.41 \mathrm{E}-02$ & $7.03 \mathrm{E}-03$ & $3.52 \mathrm{E}-03$ \\
$10^{-5}$ & $2.23 \mathrm{E}-01$ & $1.12 \mathrm{E}-01$ & $5.61 \mathrm{E}-02$ & $2.81 \mathrm{E}-02$ & $1.41 \mathrm{E}-02$ & $7.03 \mathrm{E}-03$ & $3.52 \mathrm{E}-03$ \\
$10^{-6}$ & $2.23 \mathrm{E}-01$ & $1.12 \mathrm{E}-01$ & $5.61 \mathrm{E}-02$ & $2.81 \mathrm{E}-02$ & $1.41 \mathrm{E}-02$ & $7.03 \mathrm{E}-03$ & $3.52 \mathrm{E}-03$ \\
$10^{-7}$ & $2.23 \mathrm{E}-01$ & $1.12 \mathrm{E}-01$ & $5.61 \mathrm{E}-02$ & $2.81 \mathrm{E}-02$ & $1.41 \mathrm{E}-02$ & $7.03 \mathrm{E}-03$ & $3.52 \mathrm{E}-03$ \\
$10^{-8}$ & $2.23 \mathrm{E}-01$ & $1.12 \mathrm{E}-01$ & $5.61 \mathrm{E}-02$ & $2.81 \mathrm{E}-02$ & $1.41 \mathrm{E}-02$ & $7.03 \mathrm{E}-03$ & $3.52 \mathrm{E}-03$ \\
$10^{-9}$ & $2.23 \mathrm{E}-01$ & $1.12 \mathrm{E}-01$ & $5.61 \mathrm{E}-02$ & $2.81 \mathrm{E}-02$ & $1.41 \mathrm{E}-02$ & $7.03 \mathrm{E}-03$ & $3.52 \mathrm{E}-03$ \\
$10^{-10}$ & $2.23 \mathrm{E}-01$ & $1.12 \mathrm{E}-01$ & $5.61 \mathrm{E}-02$ & $2.81 \mathrm{E}-02$ & $1.41 \mathrm{E}-02$ & $7.03 \mathrm{E}-03$ & $3.52 \mathrm{E}-03$ \\
$10^{-11}$ & $2.23 \mathrm{E}-01$ & $1.12 \mathrm{E}-01$ & $5.61 \mathrm{E}-02$ & $2.81 \mathrm{E}-02$ & $1.41 \mathrm{E}-02$ & $7.03 \mathrm{E}-03$ & $3.52 \mathrm{E}-03$ \\
$10^{-12}$ & $2.23 \mathrm{E}-01$ & $1.12 \mathrm{E}-01$ & $5.61 \mathrm{E}-02$ & $2.81 \mathrm{E}-02$ & $1.41 \mathrm{E}-02$ & $7.03 \mathrm{E}-03$ & $3.52 \mathrm{E}-03$ \\
\hline
\end{tabular}

Table 6: Results for Example 42: Maximum pointwise errors FMFDM

\begin{tabular}{|c|ccccccc|}
\hline$\varepsilon$ & $N=40$ & $N=80$ & $N=160$ & $N=320$ & $N=640$ & $N=1280$ & $N=2560$ \\
\hline $10^{-2}$ & $4.76 \mathrm{E}-01$ & $9.01 \mathrm{E}-01$ & $7.56 \mathrm{E}-01$ & $4.42 \mathrm{E}-01$ & $2.46 \mathrm{E}-01$ & $1.30 \mathrm{E}-01$ & $6.74 \mathrm{E}-02$ \\
$10^{-3}$ & $4.19 \mathrm{E}-01$ & $2.13 \mathrm{E}-01$ & $1.85 \mathrm{E}-01$ & $4.80 \mathrm{E}-01$ & $7.48 \mathrm{E}-01$ & $6.91 \mathrm{E}-01$ & $4.04 \mathrm{E}-01$ \\
$10^{-4}$ & $4.33 \mathrm{E}-01$ & $2.18 \mathrm{E}-01$ & $1.10 \mathrm{E}-01$ & $5.55 \mathrm{E}-02$ & $6.29 \mathrm{E}-02$ & $1.61 \mathrm{E}-01$ & $3.22 \mathrm{E}-01$ \\
$10^{-5}$ & $4.40 \mathrm{E}-01$ & $2.22 \mathrm{E}-01$ & $1.11 \mathrm{E}-01$ & $5.58 \mathrm{E}-02$ & $2.80 \mathrm{E}-02$ & $1.40 \mathrm{E}-02$ & $2.06 \mathrm{E}-02$ \\
$10^{-6}$ & $4.40 \mathrm{E}-01$ & $2.22 \mathrm{E}-01$ & $1.12 \mathrm{E}-01$ & $5.58 \mathrm{E}-02$ & $2.80 \mathrm{E}-02$ & $1.40 \mathrm{E}-02$ & $7.02 \mathrm{E}-03$ \\
$10^{-7}$ & $4.40 \mathrm{E}-01$ & $2.23 \mathrm{E}-01$ & $1.12 \mathrm{E}-01$ & $5.61 \mathrm{E}-02$ & $2.80 \mathrm{E}-02$ & $1.40 \mathrm{E}-02$ & $7.02 \mathrm{E}-03$ \\
$10^{-8}$ & $4.40 \mathrm{E}-01$ & $2.23 \mathrm{E}-01$ & $1.12 \mathrm{E}-01$ & $5.61 \mathrm{E}-02$ & $2.81 \mathrm{E}-02$ & $1.40 \mathrm{E}-02$ & $7.02 \mathrm{E}-03$ \\
$10^{-9}$ & $4.40 \mathrm{E}-01$ & $2.23 \mathrm{E}-01$ & $1.12 \mathrm{E}-01$ & $5.61 \mathrm{E}-02$ & $2.81 \mathrm{E}-02$ & $1.41 \mathrm{E}-02$ & $7.03 \mathrm{E}-03$ \\
$10^{-10}$ & $4.40 \mathrm{E}-01$ & $2.23 \mathrm{E}-01$ & $1.12 \mathrm{E}-01$ & $5.61 \mathrm{E}-02$ & $2.81 \mathrm{E}-02$ & $1.41 \mathrm{E}-02$ & $7.03 \mathrm{E}-03$ \\
$10^{-11}$ & $4.40 \mathrm{E}-01$ & $2.23 \mathrm{E}-01$ & $1.12 \mathrm{E}-01$ & $5.61 \mathrm{E}-02$ & $2.81 \mathrm{E}-02$ & $1.41 \mathrm{E}-02$ & $7.03 \mathrm{E}-03$ \\
$10^{-12}$ & $4.40 \mathrm{E}-01$ & $2.23 \mathrm{E}-01$ & $1.12 \mathrm{E}-01$ & $5.61 \mathrm{E}-02$ & $2.81 \mathrm{E}-02$ & $1.41 \mathrm{E}-02$ & $7.03 \mathrm{E}-03$ \\
\hline
\end{tabular}


Table 8: Rates of convergence obtained for Example 42 utilizing FMFDM

\begin{tabular}{|c|cccccc|}
\hline$\varepsilon$ & $\mathrm{r}=1$ & $\mathrm{r}=2$ & $\mathrm{r}=3$ & $\mathrm{r}=4$ & $\mathrm{r}=5$ & $\mathrm{r}=6$ \\
\hline $10^{-2}$ & 0.25 & 0.77 & 0.85 & 0.91 & 0.95 & 0.98 \\
$10^{-3}$ & 0.20 & -1.37 & -0.64 & 0.11 & 0.77 & 0.76 \\
$10^{-4}$ & 0.98 & 0.99 & -0.18 & -1.36 & -1.00 & -0.72 \\
$10^{-5}$ & 1.00 & 0.99 & 1.00 & 1.00 & -0.55 & -1.31 \\
$10^{-6}$ & 0.99 & 1.00 & 0.99 & 1.00 & 1.00 & 1.00 \\
$10^{-7}$ & 0.99 & 1.00 & 1.00 & 1.00 & 1.00 & 1.00 \\
$10^{-8}$ & 0.99 & 1.00 & 0.99 & 1.00 & 1.00 & 1.00 \\
$10^{-9}$ & 0.99 & 1.00 & 1.00 & 1.00 & 1.00 & 1.00 \\
$10^{-10}$ & 0.99 & 1.00 & 1.00 & 1.00 & 1.00 & 1.00 \\
$10^{-11}$ & 0.99 & 1.00 & 1.00 & 1.00 & 1.00 & 1.00 \\
$10^{-12}$ & 0.99 & 1.00 & 1.00 & 1.00 & 1.00 & 1.00 \\
\hline
\end{tabular}

Table 7: Rates of convergence obtained for Example 42 utilizing EFOFDM

\begin{tabular}{|c|cccccc|}
\hline$\varepsilon$ & $\mathrm{r}=1$ & $\mathrm{r}=2$ & $\mathrm{r}=3$ & $\mathrm{r}=4$ & $\mathrm{r}=5$ & $\mathrm{r}=6$ \\
\hline $10^{-2}$ & 1.00 & 1.0 & 1.00 & 1.00 & 1.00 & 1.00 \\
$10^{-3}$ & 1.00 & 1.0 & 1.00 & 1.00 & 1.00 & 1.00 \\
$10^{-4}$ & 1.00 & 1.0 & 1.00 & 1.00 & 1.00 & 1.00 \\
$10^{-5}$ & 1.00 & 1.0 & 1.00 & 1.00 & 1.00 & 1.00 \\
$10^{-6}$ & 1.00 & 1.0 & 1.00 & 1.00 & 1.00 & 1.00 \\
$10^{-7}$ & 1.00 & 1.0 & 1.00 & 1.00 & 1.00 & 1.00 \\
$10^{-8}$ & 1.00 & 1.0 & 1.00 & 1.00 & 1.00 & 1.00 \\
$10^{-9}$ & 1.00 & 1.0 & 1.00 & 1.00 & 1.00 & 1.00 \\
$10^{-10}$ & 1.00 & 1.0 & 1.00 & 1.00 & 1.00 & 1.00 \\
$10^{-11}$ & 1.00 & 1.0 & 1.00 & 1.00 & 1.00 & 1.00 \\
$10^{-12}$ & 1.00 & 1.0 & 1.00 & 1.00 & 1.00 & 1.00 \\
\hline
\end{tabular}

The analyses summarised in theorems 28 and 38 show that the proposed numerical methods are both first order uniformly convergent independently of the perturbation parameter. These theoretical results are confirmed numerically in tables $1-8$. In tables 1 and 2 we computed the maximum errors $e_{\varepsilon, N}$ and their corresponding rates of convergence $r_{\varepsilon, k}$ in tables 3 and 4, respectively, for Example 41. Similarly for Example 42, where the maximum errors are presented in tables 5 and 6 and the corresponding rates of convergence in tables 7 and 8 .

\section{Discussion and conclusion}

We designed and implemented fitted mesh and fitted operator finite difference methods for solving singularly perturbed Volterra integro-differential equations. To construct the fitted mesh method, we used the difference operator on a piecewise uniform mesh along with right side rectangle rule and trapezoidal integration with weight and remainder term in the integral form. In order for the method to be $\varepsilon$-uniform, a piecewise-uniform mesh of Shishkin type was considered. The exponential fitted operator was developed utilizing the method of integral identity with the use of an exponential basis function and interpolating quadrature rules with weight and remainder term in the integral form [2].

The error analysis shows that the proposed methods are $\varepsilon$-convergent. Two test examples were considered to confirm these results. The nodal maximum errors $e_{\varepsilon, N}$ and the corresponding rates of convergence $r_{\varepsilon, k}$ are provided in tables 1-8.

\section{Acknowledgement}

The authors are grateful to the anonymous referee for carefully checking the manuscript and providing helpful comments that helped improve this paper.

\section{References}

[1] M. Aigo, On the numerical approximation of Volterra integral equations of the second kind using quadrature rules, International Journal of Advanced Scientific and Technical Research, vol. 1, No. 3, pp. 558-564 (2013).

[2] G.M. Amiraliyev and S. Şevgin, Uniform difference method for singularly perturbed Volterra integro-differential equations, Appl Math Comput, vol. 179, No. 2, pp. 731-741 (2006).

[3] G.M. Amiraliyev, On difference schemes for problems of the theory of dispersive waves, Soviet Math Dokl, vol. 42, pp. 235-238 (1991) .

[4] G.M. Amiraliyev and Y.D. Mamedov, Difference schemes on the uniform mesh for singular perturbed pseudoparabolic equations, Turkish J Math, vol. 19, pp. 207-222 (1995).

[5] A.M. Bijura, Initial-layer theory and model equations of Volterra type, IMA J Appl Math, vol. 71, No. 3, pp. 315-331 (2006).

[6] V. Horvat, Tension spline collocation methods for singularly perturbed Volterra integro-differential and Volterra integral equations, J Comput Appl Math, vol. 140, No. 1, pp. 381402 (2002).

[7] J.P. Kauthen, Implicit Runge-Kutta methods for some integrodifferential-algebraic equations, Appl Numer Math, vol. 13, No. 1-3, pp. 125-134 (1993).

[8] J.P. Kauthen, Implicit Runge-Kutta methods for singularly perturbed integro-differential systems, Appl Numer Math, vol. 18, No. 1, 201-210 (1995).

[9] J.P. Kauthen, A survey of singularly perturbed Volterra equations, Appl Numer Math, vol. 24, No. 2, 95-114 (1997).

[10] M. Kudu, I. Amirali and G.M. Amiraliyev, A finitedifference method for a singularly perturbed delay integrodifferential equation, J Comput Appl Math, vol. 308, 379390 (2016).

[11] B. Raftari, Numerical solutions of the linear volterra integrodifferential equations: homotopy perturbation method and finite Difference method, World Appl Sci J, vol. 9, 7-12 (2010). 
[12] Y. Raffoul and H. Rai, Uniform Stability In Nonlinear Infinite Delay Volterra Integro-differential Equations Using Lyapunov Functionals, Nonauton Dyn Syst, vol. 3, No. 1, 14-23 (2016).

[13] I.J. Ramos, Exponential Techniques and Implicit Runge Kutta Methods for Singularly Perturbed Volterra Integro Differential Equations Neural Parallel Sci Comput, vol. 16, No. 3, pp. 387-404 (2008).

[14] R. Saadati, B. Raftari, H. Abibi, S.M. Vaezpour and S. Shakeri, A comparison between the variational iteration method and trapezoidal rule for solving linear integrodifferential equations, World Appl Sci J, vol. 4, No. 3, 321325 (2008).

[15] A.A. Salama and D.J. Evans, Fourth order scheme of exponential type for singularly perturbed Volterra integrodifferential equations Int J Comput Mat, vol. 77, No. 1, pp. 153-164 (2010).

[16] S. Şevgin, Numerical solution of a singularly perturbed Volterra integro-differential equation, Adv Differ Equ, vol. 2014, No. 1, pp. 1-15 (2014).

[17] Y. Zhao and F. Zhao, The Analytical Solution of Parabolic Volterra Integro-Differential Equations in the Infinite Domain, Entropy, vol. 18, No. 10, p. 344 (2016).

[18] C. Zhongdi, and X. Lifeng, A parameter robust numerical method for a singularly perturbed Volterra equation in security technologies, Matrix, vol. 1, pp. 20-22 (2006).

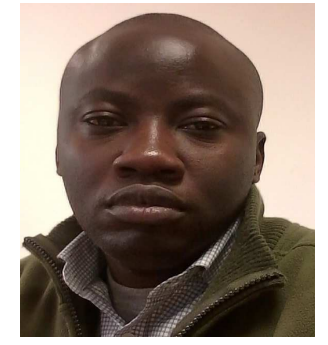

Bakulikira C. Iragi is a $\mathrm{PhD}$ fellow in the Department of Mathematics and Applied Mathematics at the University of the Western Cape. His research interests are in the areas of applied mathematics. $\mathrm{He}$ is particularly interested in developing and analysing efficient numerical methods to solve integro-differential equations.

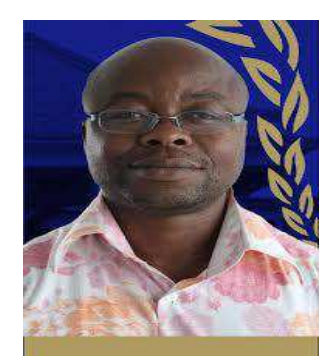

Justin B. Munyakazi is a Senior Lecturer of Mathematics at the University of the Western Cape where he received his $\mathrm{PhD}$ in Numerical Analysis. He is also a visiting Professor at the Catholic University of Bukavu. His main research fields are Numerical Analysis, Computational Mathematics and Biomathematics. He has published research articles in prestigious international journals and is referee for several journals. 